\title{
The influence of UCS upon the acquisition of the conditioned eyelid response'
}

\author{
Kenneth R. Burstein \\ UNIVERSITY OF MASSACHUSETTS
}

\begin{abstract}
The comparative effect of two UCS intensities upon eyelid conditioning was investigated in a $2 \times 2$ factorial design in which UCS intensity for trials 1-50 was orthogonal to UCS intensity for trials 51-110. The influence of UCS intensity was significant in both the pre- and the post-shift phases when all data were considered. When the responses of "non-conditioners" (Ss who averaged less than $10 \% \mathrm{CRs}$ ) were removed from consideration, the effect of UCS intensity was not significant in either phase of the experiment. It was suggested that UCS intensity is a determinant of whether or not an $\mathrm{S}$ conditions rather than a determinant of his asymptotic performance level.
\end{abstract}

\section{Problem}

The intensity of the unconditioned stimulus has long been considered a determinant of performance level in classical conditioning. In eyelid conditioning, support for this view comes from a study by Passey (1948). Other studies (Spence et al, 1958); (Ross \& Hunter, 1959) have confirmed this finding. Some studies, however, have failed to obtain expected results (Gormezano etal, 1962); (Burstein, 1963). One explanation offered for these discrepant results (Burstein, 1963) is that UCS intensity is a determinant of whether individual Ss will or will not condition rather than a determinant of the level of conditioning attained. This view holds that with lower UCS intensities fewer Ss condition than is the case with higher UCS intensities and that differences reported in previous studies are the artifactual result of averaging group data.

Although this interpretation was admittedly of the post hoc variety, it received support from a reanalysis of Passey's data. An analysis of variance based upon the responses of Ss who had at least one CR over the 50 acquisition trials revealed no significant effect of UCS intensity, $F(3.32)=1.99 ; p>.10$. The present experiment was designed to test this post hoc interpretation that differences previously obtained reflect the inclusion of differential numbers of "non-conditioners."

\section{Method}

Sixty-three introductory psychology students served as Ss. Seven Ss were discarded due to equipment failure or procedural error. The 56 remaining Ss were randomly assigned to the cells of a $2 \times 2$ factorial design.

Ss were seated in a $6 \times 4 \times 8$ sound-insulated booth in front of a table-like shelf upon which was mounted an adjustable chin-rest. A 60 watt bulb illuminated the booth between trials to minimize beta responses. A 7 watt bulb mounted $1-1 / 2 \mathrm{ft}$ in front of the $\mathrm{S}$, at eyelevel, served as the CS. An aluminum false eyelash, taped to S's lid, was attached to a micro-torque potentiometer via a nylon thread. The output of the potentiometer was recorded on a Grass Model 5 Polygraph. GrasonStadler timers and relays controlled the onset and duration of the CS and the UCS. The CS duration was $1.05 \mathrm{sec}$. The UCS was an airpuff of $50 \mathrm{msec}$. duration delivered to the right cornea from a distance of $1 / 2$ in. The intensity of the UCS was either .75 or 5.50 psi. The CS and UCS terminated simultaneously. The $1.0 \mathrm{sec}$. interstimulus interval was chosen in an attempt to avoid the problem encountered by a previous investigator (Spence, 1953) of being unable to compare the performance of groups conditioned with different UCS intensities because Ss in each group reach $100 \%$ performance levels within 20 trials.

All Ss received 110 acquisition trials. The intertrial interval ranged from 10 to $30 \mathrm{sec}$. in $5 \mathrm{sec}$. steps and varied randomly. A CR was defined as a deflection of the pen from the baseline of $1 \mathrm{~mm}$ or more having a latency of 650 to $1000 \mathrm{msec}$.

For the first 50 trials, 14 men and 14 women were conditioned with the low UCS intensity and an equal number was conditioned with the high UCS intensity. On trial 51, half of each of these two groups were switched to the alternative UCS intensity. All Ss then received 60 more trials, making a total of 110 trials. Thus, there were seven men and seven women in each of the four cells of a $2 \times 2$ factorial design in which the pre-shift UCS intensity was orthogonal to the post-shift UCS intensity.

\section{Results}

"Non-conditioners" were defined as Ss who did not average over one CR per block of 10 trials for the first 50 trials. According to this criterion, 39 Ss conditioned.

Group performance curves for all Ss and for conditioners only are presented in Fig. 1. The $1.0 \mathrm{sec}$. interstimulus interval was quite successful in keeping Ss from quickly attaining a $100 \%$ asymptotic performance level; in fact, no Ss attained this level of performance.

An analysis of variance of the arc-sine transforms of individual percentage CRs for all Ss in the preshift phase of the experiment reveals that the effect of UCS intensity is significant, $F(1 / 54)=4.12 ; p<.05$. An identical analysis performed after the responses of non-conditioners were removed from the data reduces the $\mathrm{F}$ ratio associated with UCS intensity to less than one. 


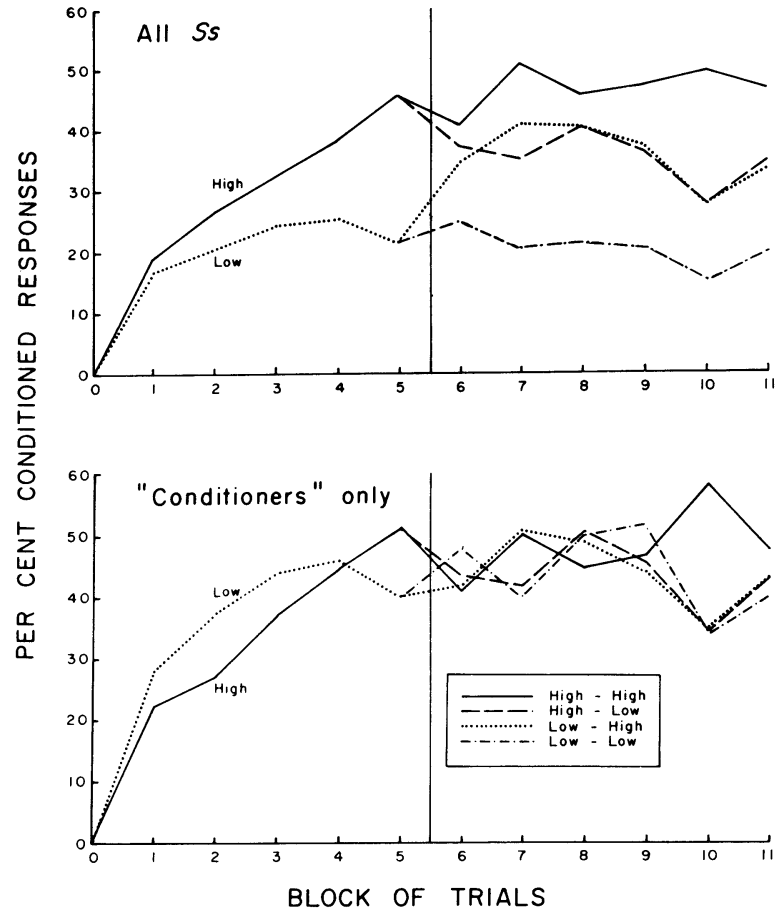

Fig. 1. The percentage of CRs plotted in 10-trial blocks for all Ss (upper graph) and for those classified as conditioners (lower graph).

The data from the post-shift phase of the experiment were subjected to a $2 \times 2$ factorial analysis of variance so as to be comparable to the results of Spence (1953). With all Ss included in the data, the pre-shift UCS intensity is significant, $F(1 / 52=4.64 ; p<.05$. The postshift UCS intensity is also significant, $F(1 / 52)=4.66$; $\mathrm{p}<.05$. When the data from non-conditioners are removed from consideration, an identical statistical analysis reveals no significant effects, all $F$ ratios being less than one.

\section{Diseussion}

These results seem to offer strong support for the view that UCS intensity is a determinant of whether an individual $\mathrm{S}$ will condition rather than a determinant of the asymptotic performance level of an individual $\mathrm{S}$.

The first phase of this study is essentially a replication of Passey's (1948) experiment both in design and in results. As with Passey's study, when non-conditioners are removed from the data, there is no significant effect of UCS intensity.

The second phase of the experiment is essentially a replication of Spence's (1953) study, both in design and in results. Again, when non-conditioners are removed from the data there are no significant effects attributable to UCS intensity.

Whether this finding is specific to human conditioning, to human conditioning with a noxious UCS or to human eyelid conditioning alone must be determined by further studies.

\section{Referenees}

BURSTEIN, K. UCS intensity and asymptotic level of eyelid conditioning. Paper read at SEPA, Miami Beach, 1963.

GORMEZANO, I., MOORE, J. W., \& DEAUX, E. Supplementary report: Yoked comparisons of classical and avoidance eyelid conditioning under three UCS intensities. J. exp. Psychol., 1962, 64, 551-552.

PASSEY, G. E. The influence of intensity of unconditioned stimulus upon acquisition of a conditioned response. J. exp. Psychol., 1948, $38,420-428$.

ROSS, L. E., \& HUNTER, J. J. Habit strength parameters in eyelid conditioning as a function of UCS intensity. Psychol. Rec., 1959, 9, 103-107.

SPENCE, K. W. Learning and performance in eyelid conditioning as a function of the intensity of the UCS. J. exp. Psychol., 1953, $45,57-63$.

SPENCE, K. W., HAGGARD, D. F., \& ROSS, L. E. UCS intensity and the associative (habit) strength of the eyelid CR. J. exp. Psychol., $1958,55,404-411$.

WICKENS, D. D., ALLEN, C. K., \& HILL, F. A. Effect of instructions and UCS strength on extinction of the conditioned GSR. J. exp. Psychol., 1963, 66, 235-240.

1. This research was supported in part by National Institute of Mental Health Grant MH 07367-01. 